\title{
POETRY
}

\section{The lady vanishes}

The silken handkerchief turns amber. My heart stops; the lady vanishes. I am surrounded by lavish death, in the magician's secret chamber.

The audience grows restless. A breath escapes this bony cage. We wait but there's no third act. Show's over; no more magic. Thank you all. The time of death ...

\section{Arash Emamzadeh BA}

Poet

Burnaby, BC

Arash Emamzadeh maintains a poetry blog http://seafloors.blogspot.com

CMAJ 2012. DOI:10.1503/cmaj.111598

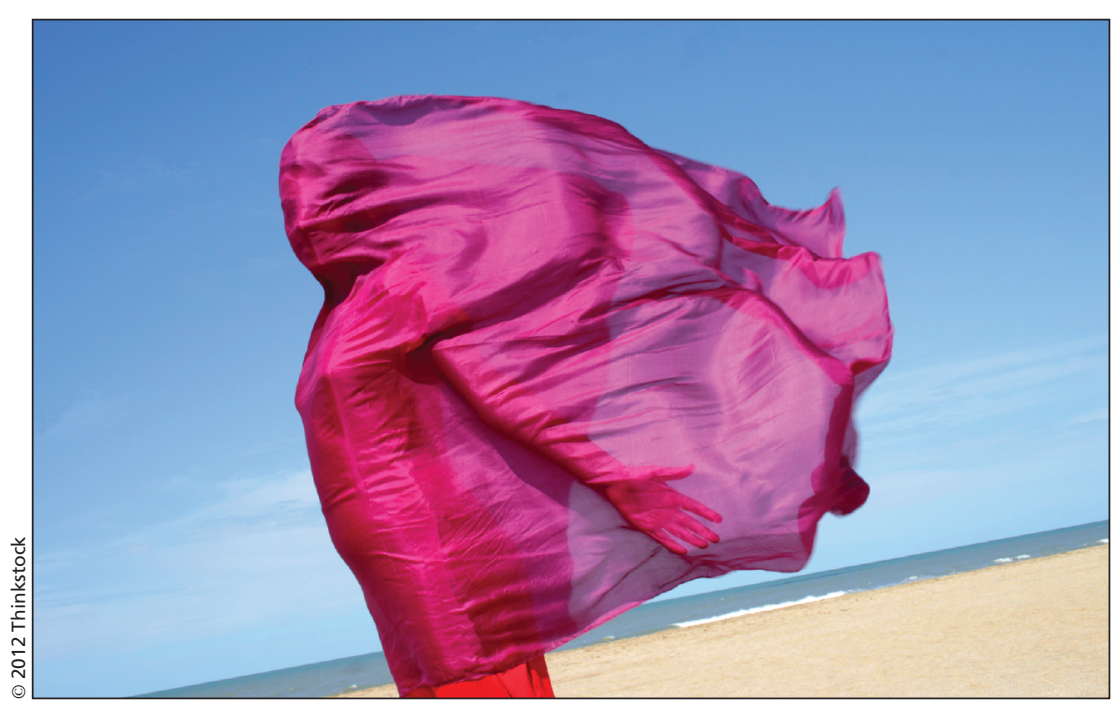

